\title{
Assessment of postoperative short-term and long- term mortality risk in Chinese geriatric patients for hip fracture using the Charlson comorbidity score
}

\author{
TW Lau *, Christian Fang, Frankie Leung
}

\section{A B S T R A C T}

Introduction: The clinical outcome of geriatric patients with hip fracture depends on surgical management as well as other medical factors. This study aimed to evaluate the relationship between Charlson comorbidity score and in-patient, 30-day, and 1-year mortality in Chinese geriatric patients who underwent surgery for hip fracture.

Methods: This was a historical cohort study conducted in a tertiary trauma referral centre in Hong Kong. From 1 January 2009 to 31 December 2010, 759 operated hip fracture patients who were over 65 years were recruited. The Charlson Comorbidity Index of each patient was retrieved from their medical records. The total Charlson comorbidity score, the highest Charlson comorbidity score, and the Charlson comorbidity score were calculated. The associations between these scores and in-patient, 30-day, and 1-year mortality were examined using Mann-Whitney $U$ test and Cox regression model.

Results: The mean in-patient, 30-day, and 1 -year mortality rate was $0.8 \%, 2.5 \%$, and $16.3 \%$, respectively. The total Charlson comorbidity score was significantly associated with in-patient mortality
$(\mathrm{P}=0.031)$. The total Charlson comorbidity score $(\mathrm{P}<0.001)$ and $C h a r l s o n$ comorbidity score $(\mathrm{P}=0.010)$ were significantly associated with 30 -day mortality. All three scores were also significantly related to 1 -year mortality $(\mathrm{P}<0.001)$. A Cox regression model demonstrated the relationship between total Charlson comorbidity score and 30-day and 1-year mortality. This can help predict 30-day and 1-year mortality risk in geriatric patients admitted for hip fracture surgery.

Conclusion: The Charlson comorbidity score provides a good preoperative indicator of 30-day and 1-year mortality in geriatric patients with hip fracture.

\section{Hong Kong Med J 2016;22:16-22}

DOI: $10.12809 / \mathrm{hkmj} 154451$

TW Lau *, FRCS (Edin), FHKAM (Orthopaedic Surgery)

C Fang, FRCS (Edin), FHKAM (Orthopaedic Surgery)

F Leung, FRCS (Edin), FHKAM (Orthopaedic Surgery)

Department of Orthopaedics and Traumatology, The University of Hong Kong, Queen Mary Hospital, Pokfulam, Hong Kong

* Corresponding author: catcherlau@hku.hk

New knowledge added by this stud

- Charlson comorbidity score correlates well with the short-term and long-term mortality of Chinese geriatric patients with operated hip fracture.

- Hip fracture surgery is generally safe in terms of short-term mortality rate even in high-risk patients.

Implications for clinical practice or policy

- Preoperative assessment of geriatric patients admitted with hip fracture can provide a reasonably accurate indication of mortality risk. This helps improve patient and family rapport and subsequent satisfaction.

\section{Introduction}

The number of geriatric patients admitted to our hospital with hip fracture has been increasing steadily over the last decade. Such osteoporotic fractures are difficult to treat because of poor bone quality. The often extreme age of the patients and other comorbidities make the management of such patients even more challenging. The clinical outcome of geriatric patients with hip fracture depends on surgical management as well as many other medical factors.

Hip fracture is a significant cause of mortality. ${ }^{1}$ Haentjens et $\mathrm{al}^{2}$ reported a 5- to 8-fold increased risk for all-cause mortality in the first 3 months following hip fracture. Some clinical scores and assessments-for example, the American Society of Anesthesiologists (ASA) classification, the Barthel index, the Goldman index, the POSSUM (Physiological and Operative Severity Score for the enumeration of Mortality and Morbidity) scoring system, the Charlson index and the visual analogue scale for risk scale, or the cumulated ambulation score-are reported to correlate with postoperative complications and mortality of hip fracture. ${ }^{3-5}$ Some of these scores can predict complication rates and others better predict short-term mortality., 
Individual clinical parameters also correlate with mortality rates. ${ }^{6-11}$

Among all these scores, the Nottingham Hip Fracture Score (NHFS) is one of the most well-known for the prediction of short- and long-term mortality in geriatric hip fracture patients, and has been validated in both western and Asian populations. ${ }^{12-14}$ This excellent score includes patient age, sex, admission haemoglobin level, Mini-Mental State Examination (MMSE) score, previous institution, number of comorbidities, and also presence of malignancy.

In our hospital, a multidisciplinary hip fracture clinical pathway programme was started in 2007. The implementation of this pathway has not only shortened hospital stay, but also improved clinical outcomes, including pressure sore rate, infection rate, and mortality rate. ${ }^{15}$ To enable early patient assessment and quantification of the risks of hip fracture surgery, a score that is easy to calculate and readily obtainable should be identified. This can greatly improve the rapport between the surgeon and patient, as well as their family, with regard to the operative risks and mortality risks. The NHFS is an excellent score that has been widely validated. Nonetheless it involves assessment of the MMSE score by a therapist and is not always possible before surgery. In this retrospective study, we used the Charlson Comorbidity Index (CCI) to evaluate patient comorbidities (Table 1).

The objective of this study was to determine the association of the CCI in operated hip fracture in patients older than 65 years with the in-patient, 30 -day, and 1-year mortality.

\section{Methods}

Our hospital is a tertiary trauma referral centre in Hong Kong. When geriatric patients with hip fracture present to the accident and emergency department, they are transferred to the orthopaedic ward for preoperative workup and assessment once they are stabilised. Surgery is performed within 2 days. Postoperatively, they are observed in an acute ward for a mean of 5 days before being transferred to another convalescence hospital for rehabilitation. Patients are discharged after a mean of 3 weeks.

From 1 January 2009 to 31 December 2010, we recruited all patients aged over 65 years who underwent surgery for geriatric hip fracture. Patients with pathological fractures, multiple fractures, or old fractures were excluded from this study. Patient records were retrieved from the electronic medical record system. Since all these patients were managed according to our hip fracture clinical pathway protocol, all demographic data, premorbid walking status, comorbidities, past surgery, complications, and also length of stay in both acute and convalescence hospitals were available. Most

\section{使用查爾森合併症評分評估華籍老年患者顝骨骨 折的術後短期及長期死亡風險 \\ 劉德榮、方欣碩、梁加利}

引言：老年䯣部骨折患者的臨床結果取決於手術治療以及其他臨床因 素。本研究評估接受骹骨骨折手術治療的華籍老年患者的查爾森合併 症評分 (CCS) 與其住院、30天和 1 年死亡率之間的關係。

方法：我們於香港一所提供第三層創傷轉介服務的醫院進行一項歷史 隊列研究。在 2009 年 1 月 1 日至 2010 年 12 月 31 日期間接受髂骨骨折手 術治療的759名65歲以上的患者均被納入研究範圍。從醫療紀錄中找 出他們的CCS指數, 計算出每名病人的CCS總評分、CCS最高分數和 CCS評分, 並使用Mann-Whitney U檢驗和Cox迴歸模型分析這些評分 與病人住院、 30 天和 1 年死亡率之間的關係。

結果：平均住院、 30 天和 1 年死亡率依次分別為 $0.8 \% 、 2.5 \%$ 和 $16.3 \% \circ \mathrm{CCS}$ 總評分與住院死亡率相關 $(\mathrm{P}=0.031) \circ \mathrm{CCS}$ 最高分數 $(\mathrm{P}<0.001)$ 和CCS評分 $(\mathrm{P}=0.010)$ 與 30 天死亡率顯著相關。三個 分數亦與 1 年死亡率顯著相關 $(\mathrm{P}<0.001)$ 。 00 迴歸模型分析顯示 CCS 總評分與 30 天及 1 年死亡率相關。這些分析結果有助預測接受髂 骨骨折手術治療的老年患者的 30 天及 1 年死亡風險。

結論：CCS 評分為老年䯣骨骨折的 30 天和 1 年死亡率提供良好的術前 指標。

TABLE I. Charlson Comorbidity Index*

\section{Score Condition}

$1 \quad$ Myocardial infarction (history, not ECG changes only)

Congestive heart failure

Peripheral vascular disease (includes aortic aneurysm $\geq 6 \mathrm{~cm}$ )

Cerebrovascular disease: CVA with mild or no residua or TIA

Dementia

Chronic pulmonary disease

Connective tissue disease

Peptic ulcer disease

Mild liver disease (without portal hypertension, includes chronic hepatitis)

Diabetes without end-organ damage (excludes diet-controlled alone)

$2 \quad$ Hemiplegia

Moderate or several renal disease

Diabetes with end-organ damage (retinopathy, neuropathy, nephropathy, or brittle diabetes)

Tumour without metastases (exclude if $>5$ years from diagnosis)

Leukaemia (acute or chronic)

Lymphoma

3 Moderate or severe liver disease

6 Metastatic solid tumour

AIDS (not just HIV-positive)

Abbreviations: $\mathrm{AIDS}=$ acquired immunodeficiency syndrome; $C V A=$ cerebrovascular accident; $\mathrm{ECG}=$ electrocardiogram; HIV = human immunodeficiency virus; TIA = transient ischaemic attack

* For each decade $>40$ years of age, a score of $\mathrm{I}$ is added to the above score 
importantly, the in-patient, 30-day, and 1-year mortality rates could be traced. In-patient mortality was defined as death that occurred in the acute or convalescence hospital, and the 30-day and 1-year mortality was defined as death occurring within 30 days and 1 year of admission, respectively. Mortality records are available when death occurs in any public hospital in Hong Kong with an electronic medical record system.

The CCI was calculated from the medical records of patients admitted with hip fracture obtained from the hospital electronic medical system. The clinical history of patients was reviewed by medical officers with comorbidities recorded. The final patient outcome was not known to the medical officers unless it was recorded in the same medical records. Using the CCI, three scores can be calculated-the total Charlson comorbidity score (TCCS) is the sum of all comorbidities combined with the score derived from the patient's age; the highest Charlson comorbidity score (HCCS) is the highest single comorbidity score of a patient; and the Charlson comorbidity score (CCS) is the sum of all comorbidity scores without consideration of age. All these scores were used to analyse and correlate with different mortality rates.

The independent sample Mann-Whitney $U$ test was used to test the statistical association of different comorbidity scores and mortality rates. Receiver operating characteristic (ROC) curve was used to measure the best cut-off for the score with respect to different mortality rates. Multiple variant analysis using Cox regression model was employed to measure the survival rate of hip fracture patients with respect to the cut-off scores derived from the ROC curves. Age, sex, fracture sites, and the Charlson scores were the independent variables. This regression model can be used as a means to predict patient mortality rate before surgery is performed.

\section{Results}

During the 2-year period, we performed surgery on 759 geriatric patients with acute hip fracture. Among them, 28\% were male and $72 \%$ were female. The mean age was 84 years: $25 \%$ aged from 70 to 79 years, $50 \%$ aged from 80 to 89 years, and $21 \%$ aged from 90 to 99 years. The oldest patient operated on was 102 years old. Overall, 72\% of patients lived at home before the admission, and the remainder in a home for the elderly. With regard to premorbid mobility, $36 \%$ of them could walk unaided and 56\% could walk with some form of aid such as a stick or walking frame.

With regard to the comorbidities, the three most common diseases were hypertension, diabetes mellitus, and dementia. Mini-Mental State Examination was used to evaluate the patients' mental function and revealed that $65 \%$ were considered severely or moderately demented. Premorbid functional status was assessed by the modified Barthel index: $40 \%$ of patients were independent, $42 \%$ were mildly and moderately dependent, and $18 \%$ were severely or totally dependent in their daily function. The ASA score was also documented: $2.5 \%$ were ASA 1 (with normal health), 38\% were ASA 2 (with mild systemic disease), and $58 \%$ were ASA 3 (with severe systemic disease). When the type of fracture was analysed, $49 \%$ were at the femoral neck and $49 \%$ the trochanter. The remaining $2 \%$ were subtrochanteric fractures. Internal fixation was performed in $75 \%$. Among this group of internally fixed hip fractures, $24 \%$ of them were impacted fractured neck of femur that was fixed by screws only. The remaining $76 \%$ were fixed by either an extramedullary or intramedullary device for the pertrochanteric fractures. The remaining $25 \%$ of fractures were displaced fractured neck of femur, managed by hemiarthroplasty. Postoperatively, $72 \%$ of patients did not require a blood transfusion. The mean preoperative waiting time was 1.44 days. The longest waiting time was 14 days due to unstable medical conditions. The mean total length of stay in both acute and convalescence hospitals was 26.6 days.

The statistical analysis of the difference in mortality rates compared with the difference scores is summarised in Table 2. Among these 759 operated patients, six died in the hospital. The in-patient mortality rate was $0.8 \%$. Within 30 days of admission, 19 patients died. The 30-day mortality rate was 2.5\%. In 1-year time, 124 patients died. The 1 -year mortality rate was $16.3 \%$. Mann-Whitney analysis showed that the in-patient mortality was significantly related to the TCCS $(\mathrm{P}=0.031)$. Regarding the 30-day mortality rate, statistical analysis showed that it was significantly related to TCCS $(\mathrm{P}<0.001)$ and CCS $(\mathrm{P}=0.010)$. Using Spearman's rank correlation coefficient, the TCCS was statistically correlated with HCCS and CCS. All three different scores derived from the CCI were significantly related to this 1 -year mortality rate $(\mathrm{P}<0.001$; Table 2$)$.

An ROC curve analysis was used to identify the relationship between TCCS and mortality rates. Both 30-day mortality and 1-year mortality rates were analysed using MedCalc software (MedCalc Software, Ostend, Belgium). Both ROC findings were significant for 30-day and 1-year mortality (area under the curve $=0.72$ and 0.75 respectively, $\mathrm{P}<0.001)$. In both situations, the best cut-off value was a TCCS of $\geq 6$ according to the Youden index method, with 30-day mortality (sensitivity 79\%, specificity 59\%, positive predictive value [PPV] 4.7\%, and negative predictive value [NPV] 99\%) and 1-year mortality (sensitivity $71 \%$, specificity $64 \%$, PPV $28 \%$, and NPV 92\%). Nonetheless when referring to the actual curve (Fig 1), this optimal cut-off point was 
TABLE 2. Mann-Whitney $U$ test for detecting statistical significance between mortality and difference scores

\begin{tabular}{lllllll}
\hline Mortality & \multicolumn{5}{c}{ Deceased vs survival: median (mean) } \\
\cline { 2 - 7 } & \multicolumn{5}{c}{ TCCS } & \multicolumn{5}{c}{ HCCS } & CCS \\
\hline In-patient & $7.5(6.8)$ vs $5.0(5.4)$ & $\mathrm{P}=0.031$ & $1.0(1.0)$ vs $1.0(1.0)$ & $\mathrm{P}=0.816$ & $3.0(2.2)$ vs $1.0(1.5)$ & $\mathrm{P}=0.275$ \\
30-Day & $7.0(6.7)$ vs $5.0(5.4)$ & $\mathrm{P}<0.001$ & $1.0(1.2)$ vs $1.0(1.0)$ & $\mathrm{P}=0.158$ & $3.0(2.4)$ vs $1.0(1.5)$ & $\mathrm{P}=0.010$ \\
1-Year & $6.5(6.6)$ vs $5.0(5.2)$ & $\mathrm{P}<0.001$ & $1.0(1.4)$ vs $1.0(0.9)$ & $\mathrm{P}<0.001$ & $2.0(2.5)$ vs $1.0(1.4)$ & $\mathrm{P}<0.001$ \\
\hline
\end{tabular}

Abbreviations: CCS = Charlson comorbidity score (Charlson comorbidity index without age correction); HCCS = highest Charlson comorbidity score; TCCS = total Charlson comorbidity score (Charlson comorbidity index with age correction)

(a)

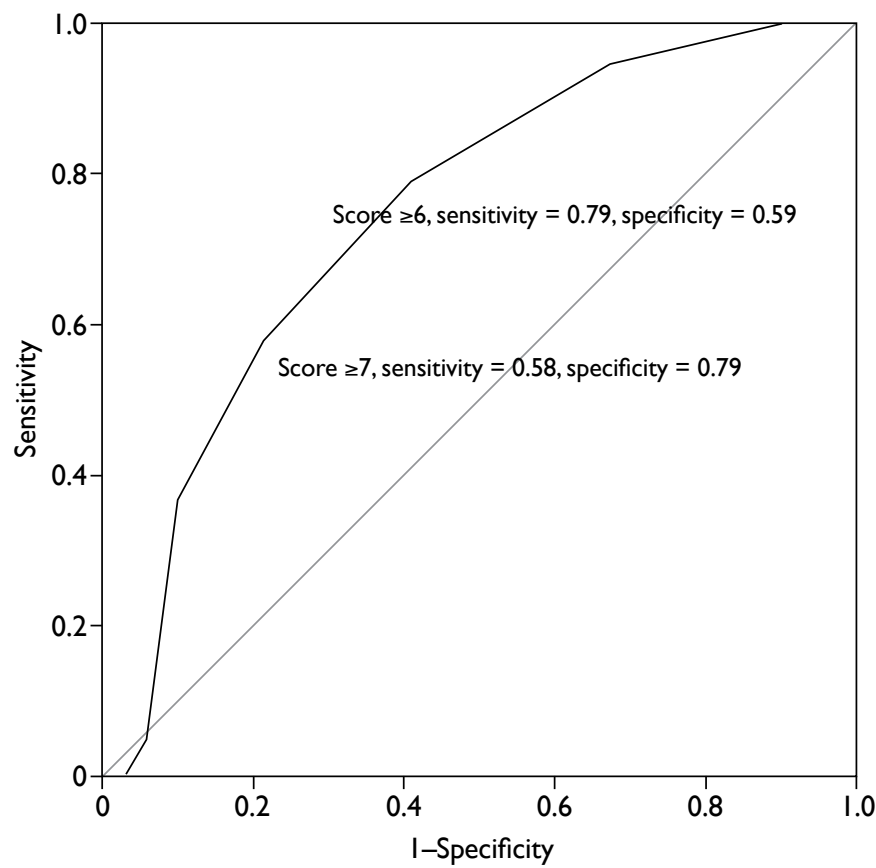

(b)

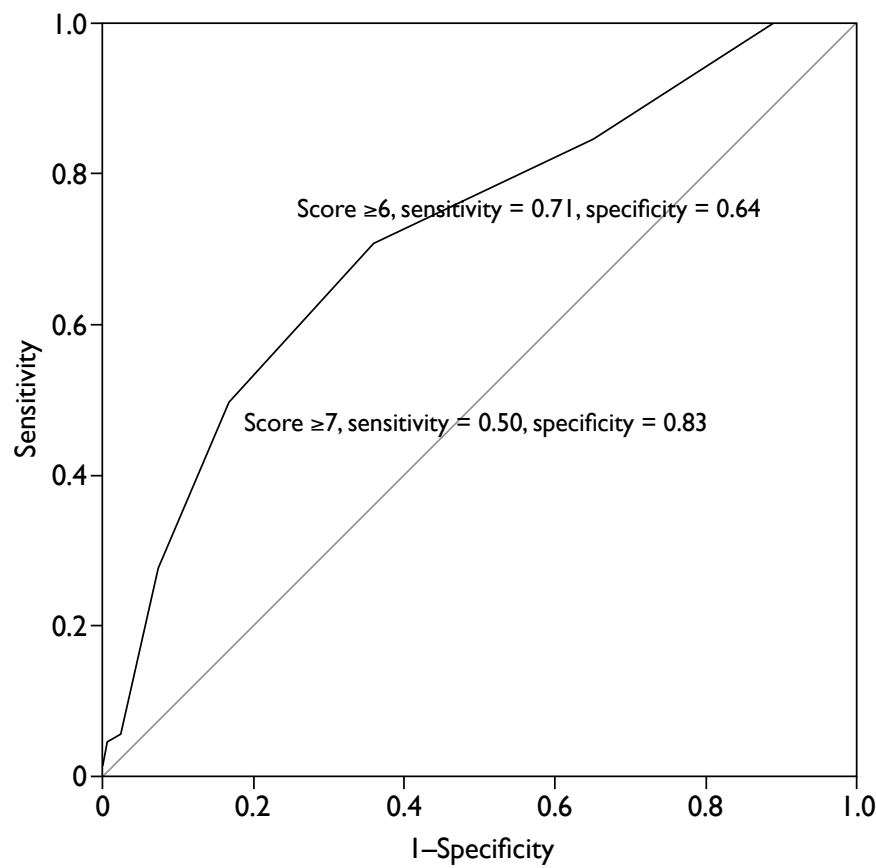

FIG I. ROC curve for TCCS with respect to (a) 30-day and (b) I-year mortality

Diagonal segments were produced by ties

Abbreviations: ROC = receiving operating characteristic;TCCS $=$ total Charlson comorbidity score (Charlson Comorbidity Index with age correction)

not well-defined versus using the adjacent higher cut-off value of TCCS of $\geq 7$.

If a TCCS cut-off value of $\geq 7$ was used, the respective value of sensitivity, specificity, PPV, and NPV was $58 \%, 79 \%, 6.5 \%$, and $99 \%$ for 30 -day mortality, and $50 \%, 83 \%, 37 \%$, and $90 \%$ for 1 -year mortality. In a clinical situation, better specificity is preferred for predicting mortality. Thus we elected to use a 3-tier stratification of patients based on their TCCS in the regression analysis-low-risk group: TCCS $0-5$, borderline group: TCCS $6-7$, high-risk group: TCCS $\geq 8$. These values are shown in Table 3 .

Cox regression model was used to demonstrate the relationship between mortality rates by using the TCCS as the predictor (Fig 2). Using a score of $\leq 5$ (low-risk group) as baseline, when score was equal to 6 or 7 (borderline group), the 30-day and 1-year mortality hazard ratio (HR) was 3.41 (95\% confidence interval [CI], 0.88-13.19; $\mathrm{P}=0.075)$ and $2.66(95 \% \mathrm{CI}$, 1.71-4.10; $\mathrm{P}<0.001)$, respectively. If the score was $\geq 8$ (high-risk group), the 30-day mortality and 1-year mortality HR was 7.93 (95\% CI, 1.93-32.54; $\mathrm{P}=0.004)$ and 5.08 (95\% CI, 3.06-8.42; $\mathrm{P}<0.001)$, respectively.

The logistic regression model revealed that the 30-day mortality rate correlated with the TCCS in a good exponential relationship (Fig 3a). If the graph was analysed in more detail, it would show that operating on the hip fractures was generally safe. Even when the TCCS reached 9 points, the 30-day mortality rate remained $<5 \%$. 
TABLE 3. TCCS correlation with 30-day and I-year mortality

\begin{tabular}{ccccc}
\hline TCCS cut-off & $\begin{array}{c}\text { Sensitivity } \\
\text { (\%) }\end{array}$ & $\begin{array}{c}\text { Specificity } \\
\text { (\%) }\end{array}$ & $\begin{array}{c}\text { Positive } \\
\text { predictive } \\
\text { value (\%) }\end{array}$ & $\begin{array}{c}\text { Negative } \\
\text { predictive } \\
\text { value (\%) }\end{array}$ \\
\hline 30-Day mortality & & & & \\
& & & & \\
$\geq 4$ & 100.0 & 9.3 & 2.8 & 100.0 \\
$\geq 5$ & 94.7 & 32.4 & 3.5 & 99.6 \\
$\geq 6$ & 79.0 & 59.2 & 4.7 & 99.1 \\
$\geq 8$ & 57.9 & 78.7 & 6.5 & 98.6 \\
$\geq 9$ & 36.8 & 90.0 & 8.6 & 98.2 \\
\hline $1-Y e a r$ mortality & 5.3 & 94.1 & 2.2 & 97.5 \\
$\geq 4$ & 100.0 & 10.9 & 18.0 & 100.0 \\
$\geq 5$ & 84.7 & 35.0 & 20.3 & 92.1 \\
$\geq 6$ & 71.0 & 63.9 & 27.8 & 91.9 \\
$\geq 7$ & 50.0 & 83.2 & 36.7 & 89.5 \\
$\geq 8$ & 27.4 & 92.6 & 42.0 & 86.7 \\
$\geq 9$ & 13.7 & 95.6 & 37.8 & 85.0 \\
\hline
\end{tabular}

Abbreviation:TCCS = total Charlson comorbidity score (Charlson Comorbidity Index with age correction)

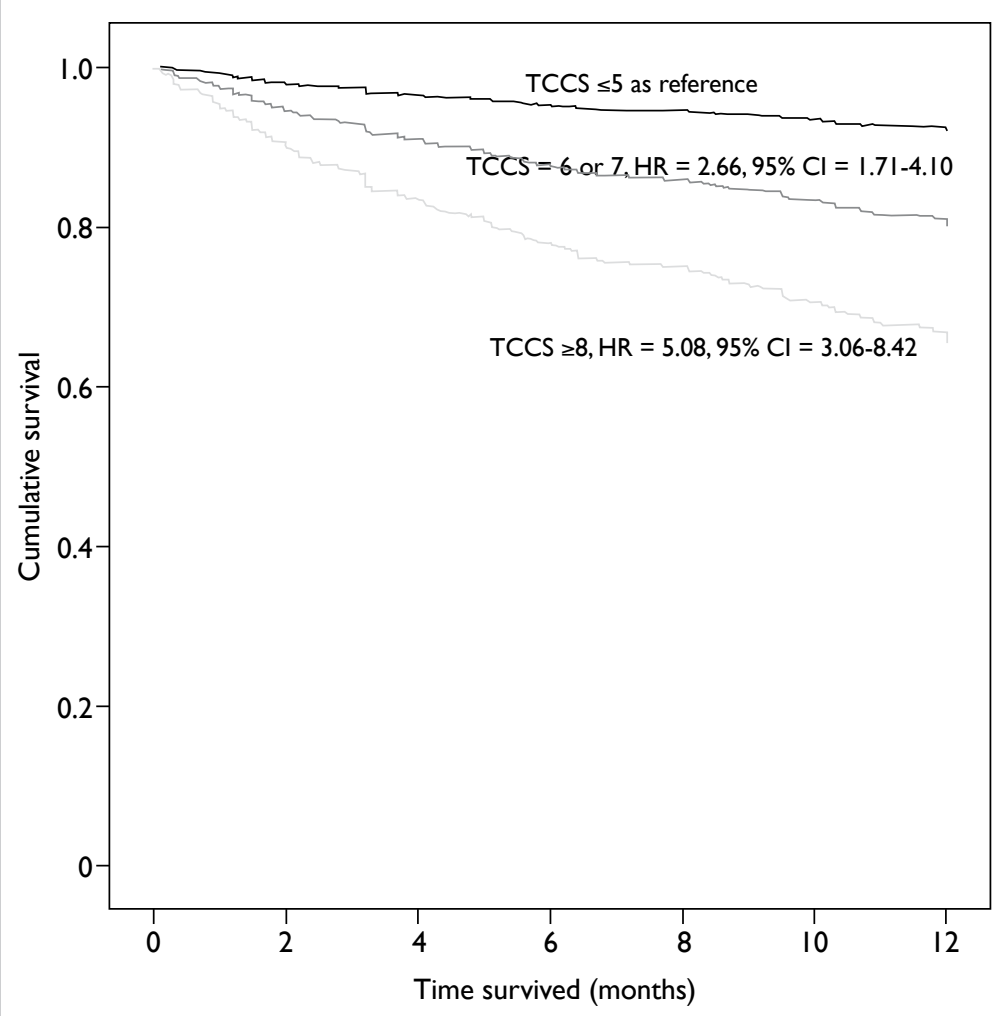

FIG 2. Cox regression model demonstrating the relationship between mortality rate and the total Charlson comorbidity score

Abbreviations: $\mathrm{Cl}=$ confidence interval; $\mathrm{HR}=$ hazard ratio; TCCS = total Charlson comorbidity score
The 1-year mortality rate showed a different correlation with TCCS. The curve became more linear in shape (Fig 3b). When TCCS was $<3$, 1-year morality rate remained $<5 \%$. When the TCCS was $>5$, mortality rate rose almost linearly with the TCCS. When the TCCS was $\leq 10,1$-year mortality rate was approximately $50 \%$. The increase in mortality rate appeared to plateau at TCCS of $>15$, where it reached $88 \%$. An overview of our hip fracture patients reveals that there was a reasonable 1-year survival with only $10 \% 1$-year mortality rate after hip fracture surgery if the TCCS was $<5$.

\section{Discussion}

In the last two decades, there has been an increasing attention on geriatric fragility fractures with a special focus on hip fractures. ${ }^{6}$ Many parameters are significant predictors of associated clinical outcome and mortality. These include type of injury and surgery, ${ }^{7}$ postoperative delirium, ${ }^{8}$ timing of rehabilitation, ${ }^{9}$ and surgical technique. ${ }^{10,11}$ In addition, many other preoperative indicators have been found to affect postoperative mortality. The most commonly identified factors include advanced age, ${ }^{16-18}$ male gender, ${ }^{16,18,19}$ poor premorbid functional capability, ${ }^{18,20}$ and presence of multiple comorbidities. ${ }^{21,22}$

The CCI is a system that allows classification of severity and uses recorded secondary diagnoses to assign a weight to morbidity, thereby generating the patient's risk of death. ${ }^{23}$ This score can be combined with age to form a single index. This is particularly useful in our geriatric hip fracture patient group because our patients' age ranged from 65 to 102 years, which is a major factor in their mortality rates.

We have shown that the TCCS correlates well with both short-term and long-term mortality. The TCCS includes all the comorbidities and the age of the patient and reflects the general health of the patient on admission to hospital. Thus the poorer the general health is, the higher the short-term mortality rate will be. As most of these patients require surgery to either fix or replace the fractured hip, there is additional stress on their physiologically compromised body. Although many of the common comorbidities of geriatric hip fracture patients are minor problems, such as diabetes, hypertension, or previous cerebrovascular accident, these problems are nonetheless chronic diseases that lead to gradual multi-organ dysfunction and deterioration. The most commonly affected organs are the lungs, heart, general vascular system, kidneys, and brain. Surgery poses a major stress challenge to these diseased organs and can result in a rapid decline in general health. Therefore the severity of a patient's comorbidities has a significant prognostic implication for short-term mortality post-surgery. This explains why the TCCS correlates significantly 

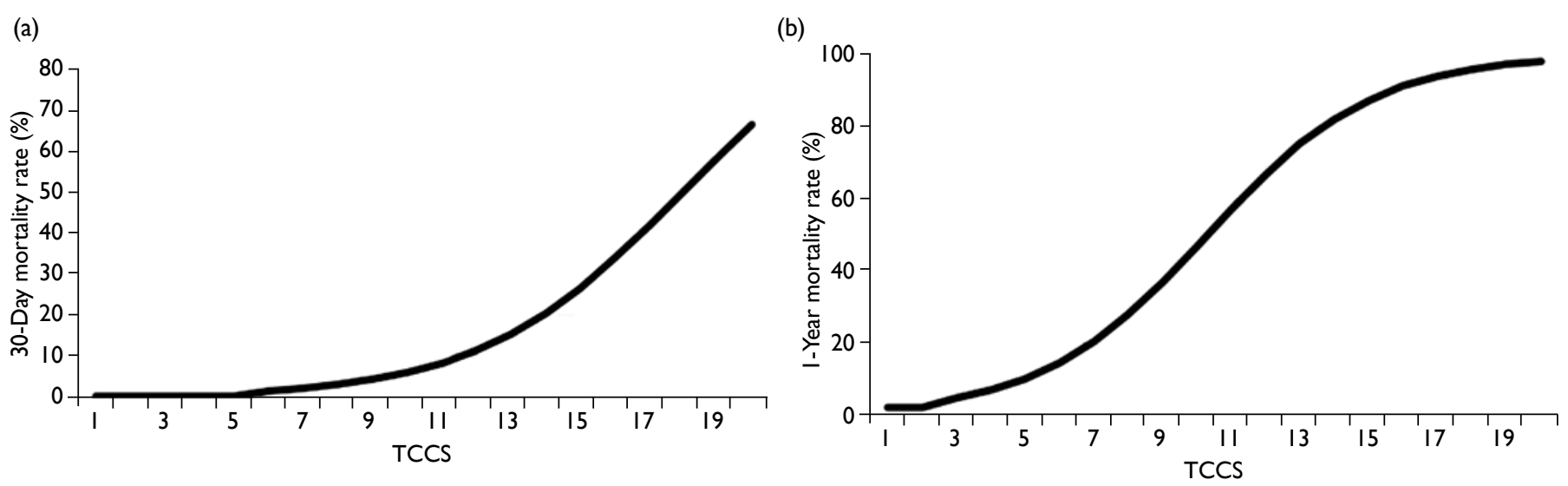

FIG 3. Logistic regression model demonstrating the relationship between (a) 30-day and (b) I-year mortality rate and total Charlson comorbidity score (TCCS)

with the in-patient and 30-day mortality rates.

Using the logistic regression graph correlating the TCCS and 30-day mortality rate, different TCCSs correspond to an estimated 30-day mortality rate. This is valuable information when frontline staff are required to explain the risks to the newly admitted patient and their family. Many patients and their family are concerned about the impending need for surgery, believing that surgery will lead to death of their loved one who already has multiple existing comorbidities. With the information available, we can reassure the patient about their low mortality risk, despite these multiple comorbidities. Informed discussion between the patient, their family, and the surgeon can allay fears about surgery and allow extra effort and care during the postoperative period. A more experienced surgeon and staff should be involved in care to minimise surgical trauma and the possibility of surgical complications. Geriatricians and anaesthetists should be informed about the higher incidence of major life-threatening conditions during the pre-, peri-, and post-operative period. This allows better utilisation and coordination of limited medical and human resources such as intensive care unit beds, sophisticated preoperative and postoperative monitoring machines, and specialist nursing care.

Analysis of the 1-year mortality rate revealed a statistically significant correlation with all scores, similar to another study. ${ }^{24}$ This is to be expected as the 1-year mortality relates more to general physical health and age, and not the hip fracture. The CCI independently predicts both short- and long-term mortality in acutely ill hospitalised elderly adults. ${ }^{25}$ In our series, the 1-year mortality rate was $16.3 \%$, slightly lower than some studies ${ }^{17}$ but not uncommon. ${ }^{24}$ This may be partly due to the general health status of our population and may be partly due to differences in the medical system.

Information about short- and long-term mortality can help reassure the patient and their family and allay their fears about surgery in the presence of other comorbidities. It can alleviate some of the stress associated with uncertainty.

This study is not without limitations. There is a possible discrepancy between the actual number of deaths because a small number may have occurred outside of the public hospital system. As a retrospective study, we were not able to control the confounding factors that could influence the results. Although age, sex, and fracture sites were accounted in the regression model, other factors such as smoking, medications, fracture sites, surgeon experience, and surgical procedure were not included in the analysis. Possible errors in coding and rating of CCI also exist. There might also have bias in data collection for the comorbidity index if patient mortality was known during the data collection process. Nonetheless based on our results in this retrospective cohort, a prospective study should be conducted to further analyse the relationship between comorbidity and mortality of the geriatric patients with hip fracture.

Furthermore, non-operated hip fracture patients were not included in this study. During the study period, 15 hip fracture patients were treated conservatively. The most common reasons for nonoperative treatment were being unfit for surgery or refusal of surgery by family. The 30-day mortality rate was $13.3 \%$. The 1 -year mortality rate was $20 \%$. Both the short-term and long-term mortality rates of these non-operated patients were generally higher than that of operated patients. However, since the number of deaths was small, a statistical comparison was not performed. Interpretation of the data should also be cautious because non-operated patients are usually very fragile with pre-existing life-threatening 
medical conditions. These patients may have had a very high short-term mortality rate if surgery were performed that would have influenced the final statistical analysis. Nevertheless the small proportion of non-operated hip fracture patients would not have been expected to have a large effect on overall results.

\section{Conclusion}

In this retrospective study of the short- and longterm mortality rates of geriatric patients undergoing surgery for hip fracture, scores derived from the CCI correlated well with mortality rates. Use of CCI before surgery to assess the patients' general health and operative risks can aid communication between the patient and doctors, and assist in deciding the best treatment option.

\section{References}

1. Frost SA, Nguyen ND, Center JR, Eisman JA, Nguyen TV. Excess mortality attributable to hip-fracture: a relative survival analysis. Bone 2013;56:23-9.

2. Haentjens P, Magaziner J, Colón-Emeric CS, et al. Metaanalysis: excess mortality after hip fracture among older women and men. Ann Intern Med 2010;152:380-90.

3. Burgos E, Gómez-Arnau JI, Díez R, Muñoz L, FernándezGuisasola J, Garcia del Valle S. Predictive value of six risk scores for outcome after surgical repair of hip fracture in elderly patients. Acta Anaesthesiol Scand 2008;52:125-31.

4. Foss NB, Kristensen MT, Kehlet $H$. Prediction of postoperative morbidity, mortality and rehabilitation in hip fracture patients: the cumulated ambulation score. Clin Rehabil 2006;20:701-8.

5. Kirkland LL, Kashiwagi DT, Burton MC, Cha S, Varkey P. The Charlson Comorbidity Index Score as a predictor of 30-day mortality after hip fracture surgery. Am J Med Qual 2011;26:461-7.

6. Smith T, Pelpola K, Ball M, Ong A, Myint PK. Preoperative indicators for mortality following hip fracture surgery: a systematic review and meta-analysis. Age Ageing 2014;43:464-71.

7. Smith EB, Parvizi J, Purtill JJ. Delayed surgery for patients with femur and hip fractures-risk of deep venous thrombosis. J Trauma 2011;70:E113-6.

8. Lee HB, Mears SC, Rosenberg PB, Leoutsakos JM, Gottschalk A, Sieber FE. Predisposing factors for postoperative delirium after hip fracture repair in individuals with and without dementia. J Am Geriatr Soc 2011;59:2306-13.

9. Siu AL, Penrod JD, Boockvar KS, Koval K, Strauss E, Morrison RS. Early ambulation after hip fracture: effects on function and mortality. Arch Intern Med 2006;166:76671.

10. Cheng T, Zhang GY, Liu T, Zhang XL. A meta-analysis of percutaneous compression plate versus sliding hip screw for the management of intertrochanteric fractures of the hip. J Trauma Acute Care Surg 2012;72:1435-43.

11. Cho SH, Lee SH, Cho HL, Ku JH, Choi JH, Lee AJ.
Additional fixations for sliding hip screws in treating unstable pertrochanteric femoral fractures (AO Type 31-A2): short-term clinical results. Clin Orthop Surg 2011;3:107-13.

12. Maxwell MJ, Moran CG, Moppett IK. Development and validation of a preoperative scoring system to predict 30 day mortality in patients undergoing hip fracture surgery. Br J Anaesth 2008;101:511-7.

13. Wiles MD, Moran CG, Sahota O, Moppett IK. Nottingham Hip Fracture Score as a predictor of one year mortality in patients undergoing surgical repair of fractured neck of femur. Br J Anaesth 2011;106:501-4.

14. Kau CY, Kwek EB. Can preoperative scoring systems be applied to Asian hip fracture populations? Validation of the Nottingham Hip Fracture Score (NHFS) and identification of preoperative risk factors in hip fractures. Ann Acad Med Singapore 2014;43:448-53.

15. Lau TW, Fang C, Leung F. The effectiveness of a geriatric hip fracture clinical pathway in reducing hospital and rehabilitation length of stay and improving short-term mortality rates. Geriatr Orthop Surg Rehabil 2013;4:3-9.

16. Holt G, Smith R, Duncan K, Hutchison JD, Gregori A. Gender differences in epidemiology and outcome after hip fracture: evidence from the Scottish Hip Fracture Audit. J Bone Joint Surg Br 2008;90:480-3.

17. Kannegaard PN, van der Mark S, Eiken P, Abrahamsen B. Excess mortality in men compared with women following a hip fracture. National analysis of comedications, comorbidity and survival. Age Ageing 2010;39:203-9.

18. Jamal Sepah Y, Umer $M$, Khan A, Ullah Khan Niazi A. Functional outcome, mortality and in-hospital complications of operative treatment in elderly patients with hip fractures in the developing world. Int Orthop 2010;34:431-5.

19. Endo Y, Aharonoff GB, Zuckerman JD, Egol KA, Koval KJ. Gender differences in patients with hip fracture: a greater risk of morbidity and mortality in men. J Orthop Trauma 2005;19:29-35.

20. Williams A, Jester R. Delayed surgical fixation of fractured hips in older people: impact on mortality. J Adv Nurs 2005;52:63-9.

21. Franzo A, Francescutti C, Simon G. Risk factors correlated with post-operative mortality for hip fracture surgery in the elderly: a population-based approach. Eur J Epidemiol 2005;20:985-91.

22. Hannan EL, Magaziner J, Wang JJ, et al. Mortality and locomotion 6 months after hospitalization for hip fracture: risk factors and risk-adjusted hospital outcomes. JAMA 2001;285:2736-42.

23. Charlson ME, Pompei P, Ales KL, MacKenzie CR. A new method of classifying prognostic comorbidity in longitudinal studies: development and validation. J Chronic Dis 1987;40:373-83.

24. Svensson O, Strömberg L, Ohlén G, Lindgren U. Prediction of the outcome after hip fracture in elderly patients. J Bone Joint Surg Br 1996;78:115-8.

25. Frenkel WJ, Jongerius EJ, Mandjes-van Uitert MJ, van Munster BC, de Rooij SE. Validation of the Charlson Comorbidity Index in acutely hospitalized elderly adults: a prospective cohort study. J Am Geriatr Soc 2014;62:342-6. 